\title{
Reconstruction of Large Acquired Scalp Defects: Ten-Year Experience
}

\author{
Milan STOJICIC 1 , Milan JOVANOVIC ${ }^{1}$, Lukas RASULIC ${ }^{2}$, Filip VITOSEVIC ${ }^{3}$ \\ ${ }^{1}$ University of Belgrade, School of Medicine, Clinical Center of Serbia, Clinic for Burns, Plastic and Reconstructive Surgery, Belgrade, Serbia \\ 2University of Belgrade, School of Medicine, Clinic for Neurosurgery, Belgrade, Serbia \\ ${ }^{3}$ University of Belgrade, School of Medicine, Clinical Center of Serbia, Center for Radiology and MRI, Belgrade, Serbia
}

\section{ABSTRACT}

AIM: The method of choice for reconstruction of large acquired scalp defects depends on numerous factors. The aim of our study was to analyze reconstructions of large acquired scalp defects performed on 135 patients in the period of 10 years.

MATERIAL and METHODS: We have monitored the factors with an impact on the reconstruction method, complications, and the achieved results. Skin grafts, local, regional and free flaps, have been applied for reconstruction of defects.

RESULTS: The depth, size, defect localization, condition of surrounding tissue, co-morbidities and causes of occurrence of defect have an impact on the method of choice for defect reconstruction.

CONCLUSION: Acquired scalp defects are the most frequent in the older population and, in most cases, occur upon the surgical removal of malignant tumors. Local fasciocutaneous flaps are the method of choice for small and acquired scalp defects of medium size while free flaps are the best solution for reconstruction of the large full-thickness scalp defects. Frequency of severe complications is significantly higher in the patients who undergo craniotomy, or those with liquorrhea.

KEYWORDS: Acquired scalp defect, Reconstruction, Skin graft, Flap

\section{INTRODUCTION}

$\mathrm{L}$ arge acquired scalp defects are caused by various etiological factors. They most frequently occur upon excision of a tumor, removal of necrotic tissue following irradiation, or with deep burns of this region. Scalp trauma, as one of the factor causing scalp defects, is often accompanied by damage of cranium bones and exposure of meninges and brain structures. These conditions require immediate reconstruction in order to prevent severe complications (16, 26) (Table I).

Reconstruction of these acquired defects is often a big challenge for a surgeon, above all, due to their size, depth and relative non elasticity of the surrounding skin $(23,33)$. The fundamental aim of reconstruction is closure of a defect by cover, which is the same or similar to the missing one, having suitable thickness, color, texture, resistance and hair distribution. Many parameters have an impact on choosing a method for reconstruction of large acquired scalp defects.

The objectives of our research were evaluation of the results of a large number of patients treated for large acquired scalp defects and comparison of different methods applied in scalp reconstruction. The quality of reconstruction was also evaluated, on the basis of achieved functional and aesthetic results.

\section{MATERIAL and METHODS}

This retrospective study included 135 patients with large acquired scalp defects treated at the Clinic for Burns, Plastic 
and Reconstructive Surgery and at the Clinic for Neurosurgery, Clinical Center of Serbia, from 2002 to 2012.

Criteria applied for inclusion of patients in the study was that authors personally participated in treatment of scalp defects, that it was not possible to close scalp defect by direct approximation of wound edges, and that patients have been monitored at least 6 months after the surgery.

We have followed these parameters in the study: a) patient gender, b) patient age, c) dimension, surface, depth, localization and causes of occurrence of defect, d) quality of surrounding skin, e) presence of co-morbidities, f) previous operations or irradiation in the scalp area, h) cigarette smoking, g) defect closure method, h) patient satisfaction by 5 -point Likert scale, i) postoperative complications. Minor complications are accepted by us as those requiring only conservative treatment, whilst major complications are implied as those requiring reoperation up to 30 days after reconstruction procedure or fatal outcome (33).

Demographic and treatment-related information is summarized using descriptive statistics. Chi-squared test was used for detection of differences of non-parametric data among groups of patients. Differences were tested by Student's t-test and the One-way Analysis (ANOVA) for parametric data.

\section{RESULTS}

Out of 135 patients, 75 (55.6\%) were males while 60 (44.4\%) were females, all of them Caucasians. According to age, patients were divided into three separate groups. In the first group were patients from 20 to 40 years old, who represented $11.1 \%$ of all patients. In the second group were patients from 41 to 60 years old, who represented $24.4 \%$, whilst in the third group were patients older than 61 years, who represented $64.4 \%$ of all patients. Statistically important, in our study, the patients were most commonly older than 61 years. The average age of our patients was 62 years.

The average value of the scalp defect surface was $93.49 \mathrm{~cm}^{2}$ ( $\mathrm{SD}=66.37$ ) (Table II).

According to defect depth, patients were divided into four groups. In the first group were patients with scalp defect of all soft tissues, in this group were 61 patients, or $45.19 \%$ of all patients. In the second group were patients with scalp defect of all soft tissues, but with intact and preserved periosteum, 16 patients or $12 \%$ were in this group. In the third group were patients with scalp defect of all soft tissues and cranium bones, there were 44 patients or $33 \%$ of all in this group. In the fourth group were patients with defect of all soft tissues, cranium bones and dura mater. In this group were 14 patients or $10 \%$.

The localization of the scalp defects of our patients is presented in Table III.

Analysis of variance of defect localization $(\mathrm{F}=5.347, \mathrm{p}=0.000)$, its size $(F=27.414, p=0.000)$ and thickness $(F=12.569, p=0.000)$ relating to the applied reconstruction method indicated that choosing a reconstruction method is conditioned by these determinants (Table IV).
Correlation analysis was used to determine the intensity of impact of every of these defect characteristics in particular on choosing a reconstructive method.

Table I: Etiological Factors Causing Acquired Scalp Defects

\begin{tabular}{lcc}
\hline Etiology & Amount of cases & \multicolumn{1}{c}{$\%$} \\
\hline Basal cell carcinoma & 75 & 55.6 \\
\hline Squamous cell carcinoma & 14 & 10.4 \\
\hline Melanoma & 2 & 1.5 \\
\hline Sarcoma & 3 & 2.2 \\
\hline Meningioma & 6 & 4.4 \\
\hline Secondary deposits & 2 & 1.5 \\
\hline Benign tumors & 3 & 2.2 \\
\hline Trauma & 10 & 7.4 \\
\hline Burns & 4 & 3.0 \\
\hline Tissue necrosis & 16 & 11.8 \\
\hline Total & $\mathbf{1 3 5}$ & $\mathbf{1 0 0 . 0}$ \\
\hline
\end{tabular}

Table II: Scalp Defect Area Distribution

\begin{tabular}{lcc}
\hline Size of defect & Amount of cases & \% \\
\hline up to $40 \mathrm{~cm}^{2}$ & 48 & 35.6 \\
\hline from 41 to $70 \mathrm{~cm}^{2}$ & 27 & 20.0 \\
\hline from 71 to $100 \mathrm{~cm}^{2}$ & 23 & 17.0 \\
\hline more than $100 \mathrm{~cm}^{2}$ & 37 & 27.4 \\
\hline Total & $\mathbf{1 3 5}$ & $\mathbf{1 0 0 . 0}$ \\
\hline
\end{tabular}

Table III: Scalp Defect Localization

\begin{tabular}{lcc}
\hline Region & Patients & $\%$ \\
\hline Frontal & 12 & 8.9 \\
\hline Temporal & 12 & 8.9 \\
\hline Parietal & 33 & 24.4 \\
\hline Occipital & 13 & 9.6 \\
\hline Frontal-parietal & 6 & 4.4 \\
\hline Frontal-temporal & 8 & 5.9 \\
\hline Temporal-parietal & 20 & 14.8 \\
\hline Parietal-occipital & 6 & 4.4 \\
\hline Frontal-temporal-parietal & 6 & 4.4 \\
\hline Frontal-parietal-occipital & 8 & 5.9 \\
\hline Frontal-temporal-parietal- & 11 & 8.1 \\
\hline occipital &
\end{tabular}


Selection of a reconstructive method has been mostly affected by depth of scalp defect (Spearman's coefficient $R=0.473, p=0.000$ ), followed by surface of the scalp defect $(R=0.351, p=0.000)$ and by localization of scalp defect $(R=0.173, p=0.045)$ which had the least significance, although statistically very important.

The quality of surrounding skin around the scalp defect was rated 1, 2 or 3 , whereby higher number denotes better quality. The average quality of the surrounding skin of patients having had complications was $1.78(\mathrm{SD}=0.85)$, whilst the average quality in whole group was $2.45(\mathrm{SD}=0.72)$.

Complications occurred in $17.7 \%$ of cases. Frequency of major complications was $2.96 \%$, while minor complications occurred in $14.81 \%$ of cases. Major complications occurred only in group of patients with defect of all soft tissues, cranium bones and dura mater, and with surface of defect over $100 \mathrm{~cm}^{2}$. Total mortality rate of the examined group was $2.2 \%$. There was no intraoperative mortality. Frequency of complications in various groups of our patients is shown in Table $\mathrm{V}$.

ANOVA of number of complications depending on localization of the defect, surface of defect, depth of defect and reconstruction method performed, indicates that surface of defect $(\mathrm{F}=6.592, \quad \mathrm{p}=0.002)$, reconstruction method performed $(F=4.329, p=0.015)$ and depth of defect $(p=0.012)$

Table IV: Scalp Defects Reconstruction Methods

\begin{tabular}{lcc}
\hline Method & Number of cases & $\%$ \\
\hline Skin graft & 18 & 13.3 \\
\hline Local flap & 41 & 30.4 \\
\hline Local flap and skin graft & 65 & 48.1 \\
\hline Regional flap & 4 & 3.0 \\
\hline Free flap & 4 & 3.0 \\
\hline Expander & 3 & 2.2 \\
\hline Total & $\mathbf{1 3 5}$ & $\mathbf{1 0 0 . 0}$ \\
\hline
\end{tabular}

have a statistically important impact on the occurrence of complications.

Correlation between complications and reconstruction methods (Spearman Correlation $=0.259, p=0.002$ ) is statistically significant. Average values (AV) of occurrence of complications in patients operated by fasciocutaneous flaps ( $A V=0.15 \pm 0.406)$ are significantly lower than values with patients operated by other methods ( $A V=0.45 \pm 0.46)$. When observing frequency of complications in patients operated by method with fasciocutaneous flaps and other methods, there are statistically very important, significant differences $\left(X^{2}=9.891, p=0.007\right)$.

Average rate of satisfaction of patients by the result of reconstruction was $3.85(\mathrm{SD}=0.796)$ (Table $\mathrm{VI})$.

ANOVA of satisfaction of patients depending on localization of defect, its surface, depth and reconstruction method performed indicates that satisfaction of patient is statistically significantly dependent on the reconstruction method performed $(F=8.828, p=0.000)$ and surface of the defect $(F=6.949, p=0.000)$ (Chart 1).

When observing the level of satisfaction of patients operated by a method with fasciocutaneous flaps and other reconstruction methods, there are statistically highly significant differences $\left(X^{2}=27.296, p=0.000\right)$. Average values of level of satisfaction of patients having been operated by method with fasciocutaneous flaps $(\mathrm{AV}=4.02 \pm 0.730)$ are significantly higher than values of patients having been operated by other methods, $A V=3.15 \pm 0.796$ (Chart 2).

\section{DISCUSSION}

A defect is a loss of part or a full thickness of tissue. Reconstructive surgery was performed by replacement of tissue in the zone of defect. Treatment outcome was assessed by the basis of aesthetic results (30). Patients were well informed about the details of the planned procedure, possible alternative methods, aesthetic disadvantages, possible complications and possible subsequent corrections $(11,32$, 37). Basic criteria considered when planning the procedures were in accordance with other studies with a large number of similar patients $(2,9,19)$ (Figures 1, 2).

Table V: Frequency of Complications and Corresponding Status

\begin{tabular}{lcccccc}
\hline & Smokers & $\begin{array}{c}\text { Previously } \\
\text { irradiated scalp }\end{array}$ & $\begin{array}{c}\text { Previous operation } \\
\text { on scalp area }\end{array}$ & $\begin{array}{c}\text { Diabetes } \\
\text { mellitus }\end{array}$ & $\begin{array}{c}\text { Significant } \\
\text { co-morbidities }\end{array}$ & Craniotomy \\
\hline Frequency in whole group & $30.4 \%$ & $20.7 \%$ & $38.5 \%$ & $10.4 \%$ & $30.4 \%$ & $40.7 \%$ \\
\hline $\begin{array}{l}\text { Frequency in group with } \\
\text { complications }\end{array}$ & $37.5 \%$ & $33.33 \%$ & $54.18 \%$ & $20.83 \%$ & $54.17 \%$ & $70.8 \%$ \\
\hline
\end{tabular}

Table VI: Satisfaction by Result of Reconstruction (Lower Rate Denotes Less Level of Satisfaction)

\begin{tabular}{cccccc}
\hline \multirow{2}{*}{ Rate not given } & \multicolumn{5}{c}{ Rate } \\
\cline { 2 - 6 } & $\mathbf{1}$ & $\mathbf{2}$ & $\mathbf{3}$ & $\mathbf{4}$ & $\mathbf{5}$ \\
\hline $3=2.2 \%$ & $0=0 \%$ & $5=3.7 \%$ & $38=28.1 \%$ & $61=45.2 \%$ & $28=20.7 \%$ \\
\hline
\end{tabular}



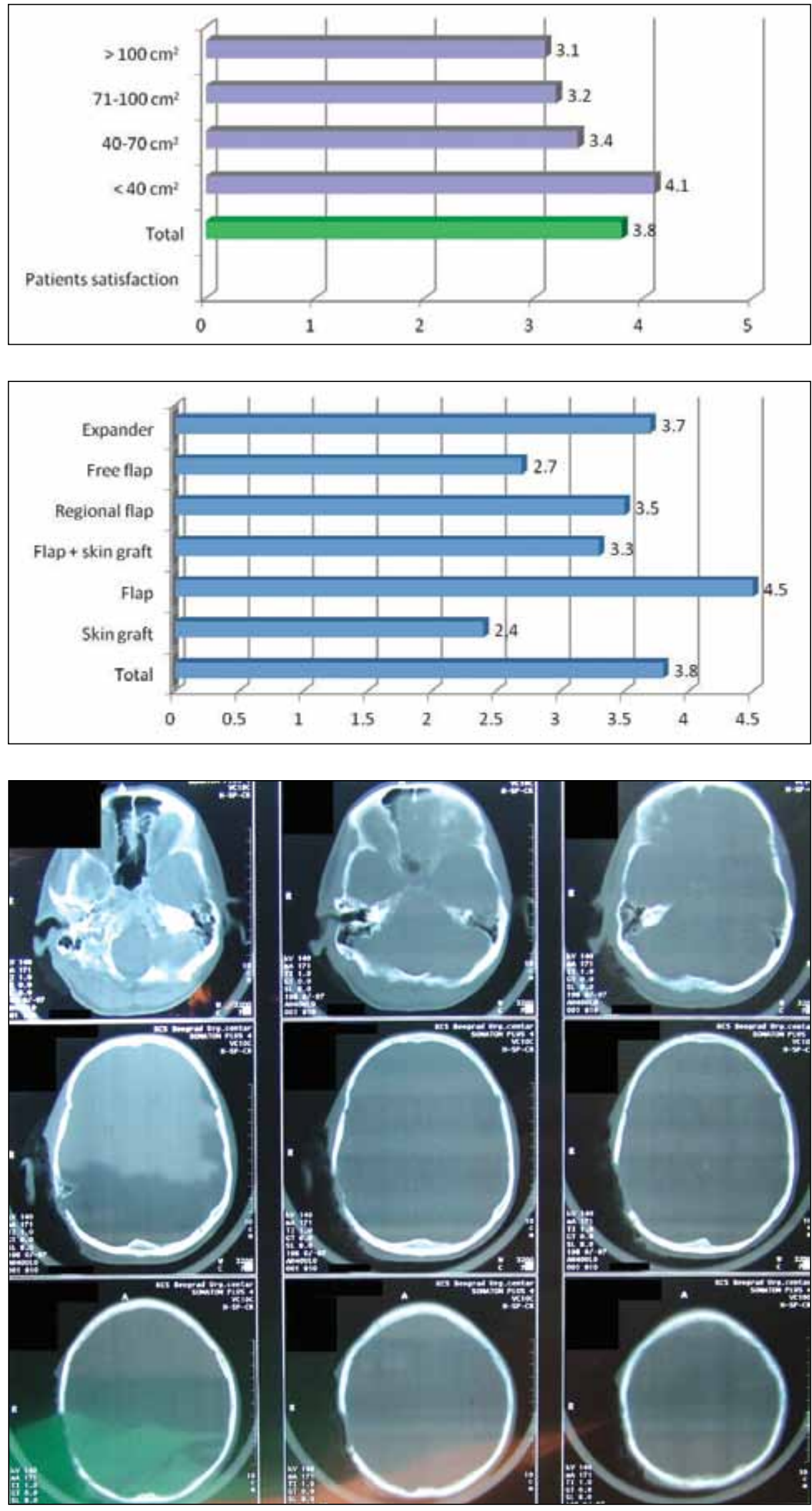

Chart 1: Satisfaction of patients related to surface of defect (1-5, lower rate denotes less level of satisfaction).

Chart 2: Satisfaction of patients related to operative technique (1-5, lower rate denotes less level of satisfaction).
Figure 1: Preoperative native computer tomography of the head (bone window). Selected case presentation. 
In our research, there was no statistically significant difference among the examinees according to gender, similar to the studies used for comparison $(22,25,26,33,40)$. Owing to the modern way of life and equal exposure to risk factors, nowadays, the average risk for a white person to acquire a large scalp defect is equal between genders.

Probability of occurrence of a large scalp defect increases with age, especially in the sixth decade of life. There are numerous causes of this occurrence. The scalp is one of the most exposed parts of the body to the sun's rays and, therefore, malignant tumors of the skin most frequently occur at this region, and are one of the most common causes of scalp defects. Also, wounds of the elderly heal slowly and the necrotic zones can be larger. The average age of our patients was similar to those in previous related studies $(25,33,40)$.

Selection of the reconstructive method has been mostly affected by depth of defect, size of defect and localization of defect (in this order). A deeper defect requires that the replacing tissue must be more massive, more resistant to mechanical traumas or potential infections and to be able to provide sufficient blood supply. Choice of reconstructive method has been affected by the surface of the defect too. This is because surrounding tissue available for reconstruction is reduced when the surface of the defect is large, and the amount of surrounding tissue is inadequate. Iblher et al. (25) stated that defects spreading to over $50 \%$ of the scalp could be closed by local flaps, which is also our opinion. In cases when the defect is too large and when they spread over a great part of the scalp (with exposed bones), the best reconstructive solution to use is free or regional flaps, which we have applied as well. This is in accordance with conclusions of other authors $(3,5,6,13$, $24,29,35)$. Although the location of the defect had the least significance of these three, it is still statistically significant for choosing a reconstructive method. It refers to the forehead being an important aesthetic unit and the occiput requiring massive and reliable cover (Figures 3,4).

We have applied skin grafts mostly for closure of large defects cum periosteum. Exceptionally rarely, in cases when large scalp defects lack all soft tissues and when free or regional flaps cannot be applied for some reason, conditions for growth of granulations and closure of defects are created by perforation of the denuded cranium. Because graft stability and aesthetic results are most often poor, quality of the cover can be greatly improved by application of the dermal regeneration templates on which the skin graft is placed after three weeks $(7,10,28,45)$.

Local flaps proved the claim that a similar thing best replaces a similar thing, with suitable texture and color, and sufficient mass with good vascularized tissue. This reconstruction method is easy and fast, but is limited by the amount of available tissue $(4,17,36,39,42)$. Functional and aesthetic results of the reconstruction were superior to other reconstruction methods. Good knowledge of scalp anatomy is essential in the planning of the reconstruction as the quality of mutual anastomoses of the blood vessels is not the same in all regions although it is excellently vascularized (43). The local fasciocutaneous flaps of all types and combinations provided a reconstruction method

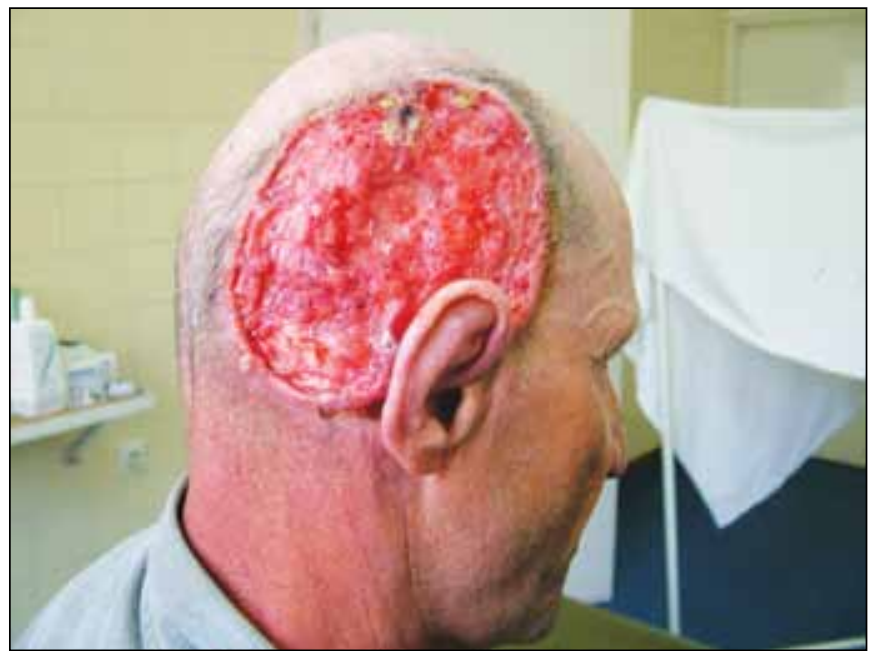

Figure 2: Preoperative finding in patient with basal cell carcinoma with bone invasion (ulcus terebrans). Selected case presentation.

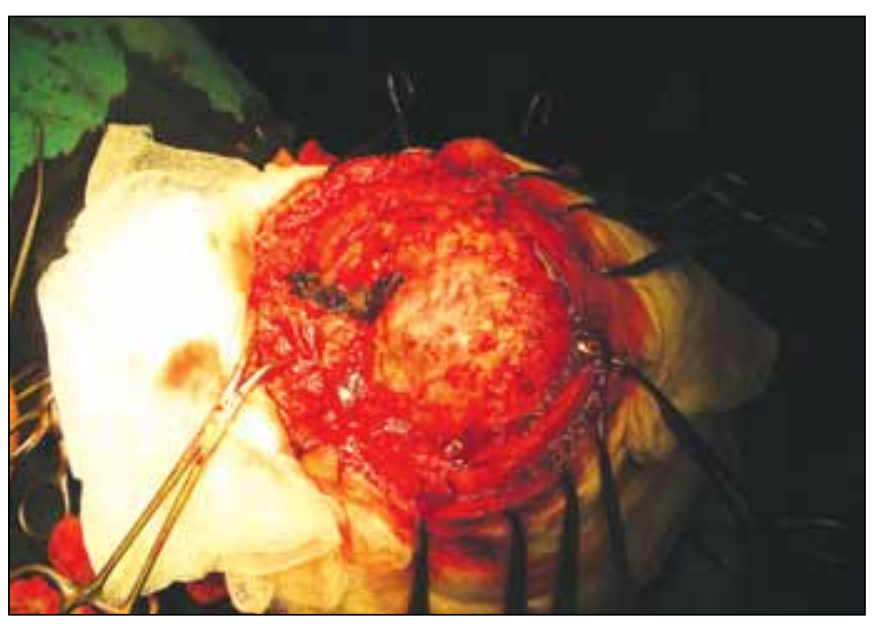

Figure 3: Intraoperative finding after removal of tumor and bone. Selected case presentation.

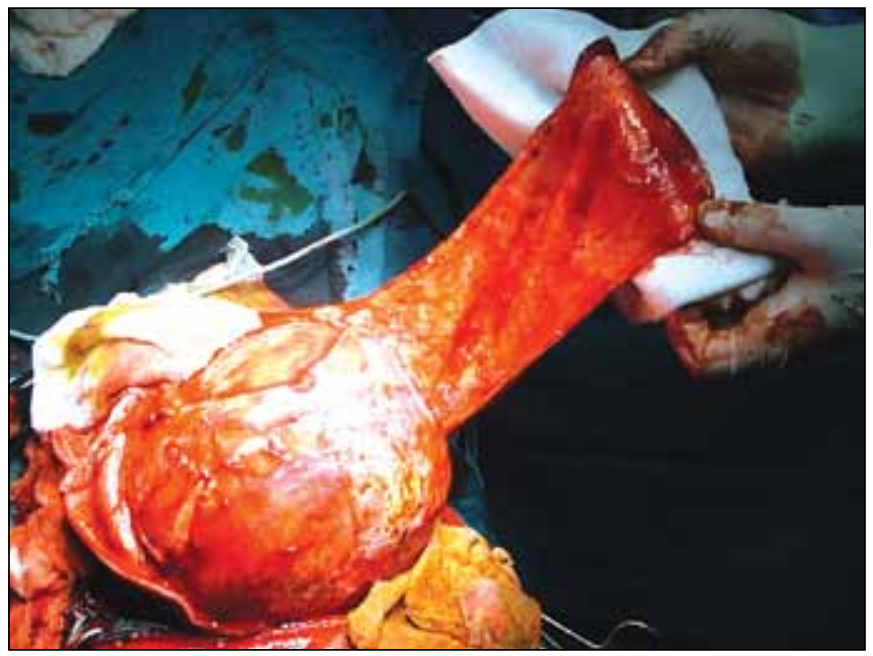

Figure 4: Intraoperative finding, fasciocutaneous flap is elevated. Selected case presentation. 
option for us if circumstances allowed. When necessary, we have achieved additional relaxation by parallel incisions of the galea aponeurotica (33). We could close, with local flaps, defects of all depths, and cover avascular structures or allomaterial used for reconstruction of osseous defects. Therefore, local flaps are the gold standard for reconstruction of small and medium scalp defects $(18,27,36)$.

We have applied local flaps in combination with skin grafts in the cases when direct closure of a location where the flap was taken from was not possible $(1,8,34)$.

We have used distant flaps in the cases when there were no available surrounding tissues and where it was not possible to apply skin grafts or free flaps. Defects of any depth can be successfully closed by these flaps (41). Sufficient amount of tissue is replaced by distant flaps in the zone of reconstruction and where there are no contour irregularities, but there is obvious difference in quality, skin color and hair distribution. Distant flaps are similar to free flaps regarding these features. The advantage of a method with distant flaps compared to a method with free flaps is that the procedure is simpler and shorter.

Free flaps have been applied in all cases with large defects and no vascularized base. Advantage of free flaps is that defects of any depth spreading over the whole scalp can be closed by free flaps through a single-stage procedure $(12,21)$. Disadvantage of the application of microvascular flaps is that the skin always differs in texture, depth and color from the one surrounding a defect, because it originates from other region. Free flaps are undoubtedly the method of choice for reconstruction of large acquired scalp defects $(2,3,11,19,22$, $25,35,40,44)$.

We have used tissue expanders for reconstruction of scalp defects when surrounding tissue was insufficient to enable the application of a local flap $(20,38)$. The quality of tissue was excellent, but the technique required much more time to achieve the necessary expansions. The tissue expanders had the significance further on in correction of alopecia spreading over up to $50 \%$ of the scalp surface $(15,31)$.

In our study, complications occurred more often in smokers, patients with diabetes, severe co-morbidities, patients having liquorrhea, patients previously operated on and irradiated in the zone of or around the reconstruction. These were mostly minor complications. All major complications $(2.2 \%-3$ patients in total) occurred in patients with defects larger than $100 \mathrm{~cm}^{2}$ in whom craniotomy was performed and who have had liquorrhea. The significance of smoking for the frequent occurrence of complications was stated by Eckardt and Fokas on the basis of a series of 500 cases (14), which corresponds to the results we have achieved as well. Frequency of complications in our research is similar to the ones in the literature, $0-21 \%(18,19,22,26)$ and it is in accordance with scalp depth, surface and applied reconstruction method.

The results of our research indicate that the occurrence of complications is affected mainly by reconstruction method performed and the surface of the defect, which is in accordance with data we found in the literature $(13,16,33)$. Also, complications occurred more often when the defect was deeper, and spread over the cranial bones and meninges.

Complications occurred relatively often in a group of patients in which reconstruction was performed by skin grafts, but all of them were minor and they were solved by extended dressings.

Frequency of complications followed by application of local flaps in the literature is from $0 \%$ to $11.8 \%(19,25,33,41)$. Minor complications in our review occurred in $2.4 \%$ patients, while there were no major complications, indicating that it is the most reliable method. The amount of complications was increased in cases when we combined local flaps with skin grafts, but they were mainly related to non-acceptance of part of the skin graft. Complications were more frequent when we applied regional flaps at a rate of $25 \%$, but they were all minor ones. Frequency of major complications followed by application of free flaps in the literature is $5.7 \%-20 \%(3,14$, $26,44)$ and that of liquorrhea is $25 \%-30 \%(22,25)$, which is similar to our result of $25 \%$.

Satisfaction of patients regarding reconstruction is subjective experience affected by many parameters. Complex analysis of problems and selection of an adequate reconstruction method with precise surgery is necessary for achieving optimal results (9). In our research, satisfaction of patients regarding reconstruction was evaluated as 3.8 , which is a very good result. Satisfaction of patients regarding reconstruction gradually decreases by enlargement of the defect surface. When it is about the proportion of defects depth and satisfaction regarding reconstruction we have obtained seemingly a paradoxical result - the least satisfied patients were the ones with defects where periosteum was preserved and the ones where defects were spread over all soft tissues, cranium and dura mater. The reason is because in the cases of large defects, where periosteum was preserved, reconstructions were mainly performed by skin grafts, by which patients were less satisfied. Satisfaction of patients was evaluated as excellent when we performed reconstructions by local flaps and, accordingly, local flaps are the method of choice for reconstruction of small and medium defects, which is also accepted by most of the studies founded in literature $(8,18,19,25,36)$. We have achieved very good results when we used expanders, local flaps in combination with skin grafts or distant flaps. In our research, the least satisfied patients were the ones in which reconstruction was performed by skin grafts and free flaps. Such findings corresponds to the data stated in the literature $(19,21,44)$ when comparing all methods of reconstructions, with the exception of study performed by Denewer et al. (9) where patients were more satisfied by application of free flaps than our patients (Figures 5, 6).

\section{- CONCLUSION}

The reconstruction method with fasciocutaneus flaps is superior to others regarding patient satisfaction in patients with acquired scalp defects because this type of reconstruction causes complications only rarely. However, the best reconstruction method for large acquired scalp defects is the use of free flaps. 


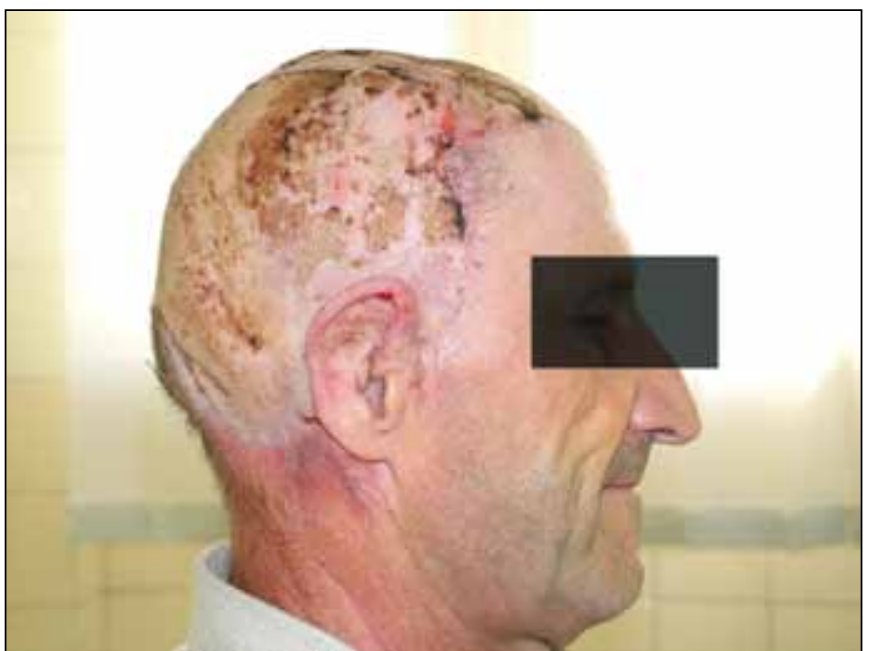

Figure 5: Postoperative finding, before radiotherapy. Selected case presentation.

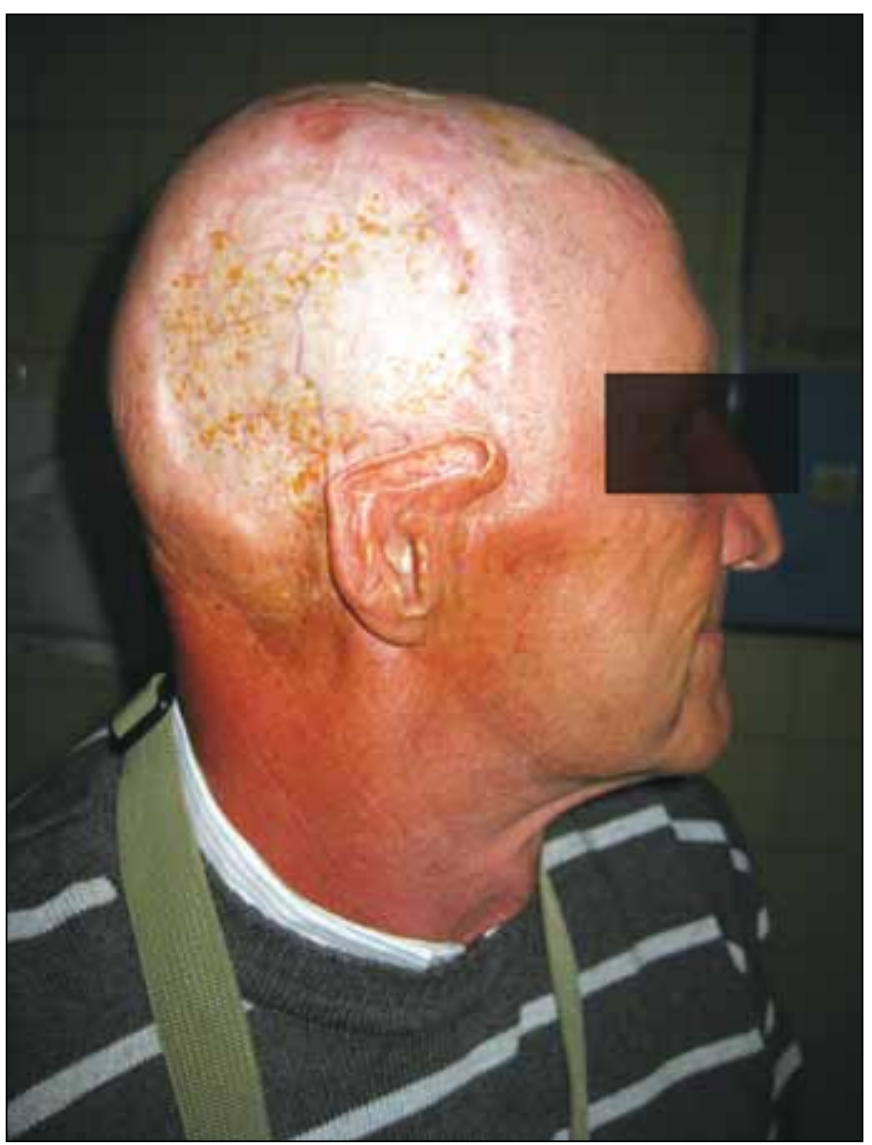

Figure 6: Postoperative finding, after radiotherapy. Seven years after the surgery. Selected case presentation.

\section{- REFERENCES}

1. Aldabaqh B, Cook JL: Reconstruction of scalp wounds with exposed calvarium using a local flap and a split-thickness graft: Case series of 20 patients. Dermatol Surg 40(3): 257265, 2014

2. Baumeister S, Peek A, Friedman A, Levin S, Marcus J: Management of postneurosurgical bone flap loss caused by infection. Plast Reconstr Surg 122(6): 195e-208e, 2008

3. Beasley NJ, Gilbert RW, Gulllane PJ, Brown DH, Iris JC, Neligan PC: Scalp and forehead reconstruction using free revascularized tissue transfer. Arch Facial Plast Surg 6(1):1620, 2004

4. Boustany A, Ghareeb P, McClellan T: Forehead reconstruction using a modified dual-plane A to $\mathrm{T}$ flap. Can J Plast Surg 20(4): 251-254, 2012

5. Calikapan GT, Yildirim S, Akoz T: One-stage reconstruction of large scalp defects: Anterolateral thigh flap. Microsurgery 26(3): 155-159, 2006

6. Chang KP, Lai $\mathrm{CH}$, Channg $\mathrm{CH}$, Lin CL, Lai CS, Lin SD: Free flap option for reconstruction of complicated scalp and calvarial defects: Report of series of cases and literature review. Microsurgery 30:13-18, 2010

7. Corradino B, Lorenzo D, Leto Barone A, Maresi E, Moschella F: Reconstruction of full thickness scalp defects after tumor excision in elderly patients: Our experience with Integra dermal regeneration template. J Plast Reconstr Aesthet Surg 63: 245-247, 2010

8. Del Campo JA, Garcia del Marcos JA, Pardo de Vera JL, Garcia de Marcos MJ: Local flap reconstruction of large scalp defects. Med Oral Patol Oral Cir Bucal 13: 666-670, 2008

9. Denewer A, Khater A, Farouk O, Hegazy M, Mosbah M, Hafez M, Shahatto F, Roshdy S, Elnahas W, Kasem M: Can we put simplified algorithm for reconstruction of large scalp defects following tumor resection? World J Surg Oncol 9:129-135, 2011

10. Dessy LA, Mazzocchi M, Rizzo MI, Onesti MG, Scuderi G: Scalp reconstruction using dermal induction template: State of the art and personal experience. In Vivo 27(5):153-158, 2013

11. Ducic Y: Reconstruction of the scalp. Facial Plast Surg Clin 17(2):177-187, 2009

12. Early MJ, Green MF, Milling MA: A critical appraisal of the use of free flaps in primary reconstruction of combined scalp and calvarial cancer defects. Br J Plast Surg 43: 283-289, 1990

13. Earnest LM, Byrne PJ: Scalp reconstruction. Facial Plast Surg Clin North Am 13(2): 345-353, 2005

14. Eckardt A, Fokas K: Microsurgical reconstruction in the head and neck region: An 18-year experience with 500 consecutive cases. J Craniomaxillofac Surg 31(4): 197-201, 2003

15. Fan J, Liu L, Tian J, Gan C, Lei M: The expanded "flying-wings" scalp flap for aesthetic hemiscalp alopecia reconstruction in children. Aesthetic Plast Surg 33(3):361-365, 2009

16. Fischer JP, Sieber B, Nelson JA, Kovach SJ, Taylor JA, Serletti JM, Wu LC, Kanchwala S, Bartlett SP, Low DW: A 15-year experience of complex scalp reconstruction using free tissue transfer-analysis of risk factors for complications. J Reconstr Microsurg 29(2): 89-97, 2013 
17. Guerrerosantos J: Frontalis musculocutaneous island flap for coverage of forehead defect. Plast Reconstr Surg 105(1):1822,2000

18. Guerrisi JO: Reconstruction of large scalp defects in the scalp with fasciocutaneous flaps. Scand J Plast Reconstr Hand Surg 33: 217-224, 1999

19. Gundeslioglu O, Altundag O, Akin S, Maral T: Closure of large scalp defects by modigied Gillies triple scalp flaps in patients with scalp tumors. Plast Reconstr Surg 116(6):1813-1814, 2005

20. Gurlek A, Alaybeloglu N, Demir C, Aydogan H, Bilen B, Ozturk $A$ : Aethetic reconstruction of large scalp defects by sequential tissue expansion without interval. Aesth Plast Surg 28:245250, 2004

21. Hashem F, Al Qattan M: Scalp reconstruction with free flaps using the external carotid artery and internal jugular vein as the recipient vessels without the need for interpositional vein grafts or arterio-venous loops. Br J Plast Surg 58:1025-1026, 2005

22. Herrera F, Buntic R, Brooks D, Buncke G, Antony A: Microvascular approach to scalp replantation and reconstruction: $A$ thirty-six experience. Microsurgery 1-7, 2012

23. Hussain W, Mortimer NJ, Salomon PJ, Stanway A: A Galeal/ periosteal flaps for reconstruction of large scalp defects with exposed outer table. Br J Dermatol 126: 460-470, 2010

24. Hussussian CJ, Reece GP: Microsurgical scalp reconstruction in the patient with cancer. Plast Reconst Surg 109(6):18281834, 2002

25. Iblher N, Ziegler M, Penna V, Eisenhardt S, Stark B, Bannasch $\mathrm{H}$ : An algorithm for oncologic scalp reconstruction. Plast Reconstr Surg 126: 450-459, 2010

26. Ioannides C, Fossion E, Mc Grouther A: Reconstruction for large defects of the scalp and cranium. J Cranio-Maxillofac Surg 27: 145-152, 1999

27. Juri J: Use of parieto-occipital flaps in the surgical treatment of baldness. Plast Reconstr Surg 55:456-460, 1975

28. Koenen W, Goerdt S, Faulhaber J: Removal of outer table of the skull for reconstruction of full thickness scalp defects with a dermal regeneration template. Dermatol Surg 34:357-363, 2008

29. Labow BI, Rosen H, Pap SA, Upton J: Microsurgical reconstruction: A more conservative method of managing large scalp defects? J Reconstr Microsurg 25: 465-474, 2009

30. Lineaweaver WC: Problem analysis in reconstructive surgery: Up and beyond the reconstructive ladders. In: Wei F, Mardini $S$ (eds). Flaps and Reconstructive Surgery. Elsevier, 2009:3-14

31. Manders EK, Schenden MJ, Furrey JA, Hetzler PT, Davis TS, Graham WP $3^{\text {rd: }}$ Skin expansion to eliminate large scalp defects. Plast Reconstr Surg 12(4): 305-312, 1984
32. Montacer B, Bouzaiene M, Elloumi I, Hableni H, Jelali A: Hair transplantation - a method for camouflage of scalp scars. J Cranio-Maxillofac Surg 36(1): 2, 2008

33. Newman MI, Hanasono MM, Disa JJ, Cordeiro PG, Mehrara BJ: Scalp reconstruction: A 15-year experience. Ann Plast Surg 52(5): 501-506, 2004

34. O'Blenes CA, Lee JP, Walsh NM, Morris SF: An unusual case of turban tumor syndrome treated with total scalp excision and advancement flap and skin graft reconstruction. Ann Plast Surg 65: 107-109, 2010

35. O'Connel DA, Teng MS, Mendez E, Futran ND: Microvascular free tissue transfer in the reconstruction of scalp and lateral temporal bone defects. J Craniofac Surg 22(3): 801-804, 2011

36. Orticochea M: "Banana peel" scalp, forhead, and nape of neck flaps. In: Grab's Encyclopedia of Flaps. Head and Neck. Third ed. Philadelphia: Lippincot Williams \& Wilkins, 2009: 9-13

37. Patrick CA, Downs BW: Options for the management of forehead and scalp defects. Facial Plast Surg Clin 17(2):379393, 2009

38. Radovan C: Tissue expansion in soft-tissue reconstruction. Plast Reconstr Surg 74(4): 482-492, 1984

39. Rose V, Overstall S, Moloney DM, Powell BW: The H-flap: A useful flap for forehead reconstruction. Br J Plast Surg 54(8): 705-707, 2001

40. Souza DG: Reconstruction of large scalp and forehead defects following tumor resection: Personal strategy and experience analysis of 25 cases. Rev Bras Cir Plast 27(2): 227-237, 2012

41. Tamas C, Popa L, Turliuc D, Morosanu C, Lazar M, Vasilica E, Cazacu A, Anastasiu C, Taranu R, Stamate T: Surgical reconstruction in scalp defects. Jurnalul de Chirurgie 1:196199, 2005 (In Romanian)

42. Temple C, Ross D: Scalp and forehead reconstruction. Clin Plastic Surg 32: 377-390, 2005

43. Tolhurst DE, Carstens MH, Greco RJ, Hurwitz DJ: The surgical anatomy of the scalp. Plast Reconstr Surg 87: 603-612, 1991

44. van Driel AA, Mureau MA, Goldstein DP, Gilbert RW, Irish JC, Gullane PJ, Neligan PC, Hofer SO: Aesthetic and oncologic outcome after microsurgical reconstruction of complex scalp and forehead defects after malignant tumor resection: An algorithm for treatment. Plast Reconstr Surg 126(2):460-470, 2010

45. Wang JC, To EW: Application of dermal substitute (Integra) to donor site defect of forehead flap. Br J Plast Surg 53(1):70-72, 2000 